\title{
Analysis and improvement of "The Last Mile" to and from the national airport as part of the mobility policy in the Brussels urban area
}

\author{
J. Matheys, C. Rogolle, N. Sergeant, F.-S. Boureima, \\ J.-M. Timmermans, H. Rombaut \& J. Van Mierlo \\ Department of Electrotechnical Engineering and Energy Technology, \\ Vrije Universiteit Brussel, Belgium
}

\begin{abstract}
Aviation is the fastest growing transport mode worldwide. One of the drawbacks of this success is the increasing number of passengers that need to be transported to and from the airport before and after their flights. "The last mile" is the distance between the starting point of the trip and the airport of departure or between the airport of arrival and the destination of the trip. In some airports, the further development of activities can be constrained by the landside part of the transport chain. In this paper, the current situation of the passenger transport to and from Brussels Airport is analyzed. The airport is located next to the ring road of Brussels and consequently passengers travelling by road to the airport influence traffic on the ring road and inversely congestion on this same ring road interferes with smooth passenger traffic to the airport. The capacity of public transport should therefore be increased and its catchment area should be extended to reduce the share of personal vehicles in the total passenger transport. The different landside access modes to the airport are inventoried and their shares in the total are described. Planned mobility projects and their environmental impacts are evaluated in the light of expected development of the airport. Moreover, the implementation potential of some examples from other airports to Brussels Airport as well as their sustainability is assessed.
\end{abstract}

Keywords: airport mobility, public transport, environmental impacts, urban congestion. 


\section{Introduction}

Brussels Airport is the main Belgian airport and is located approximately $12 \mathrm{~km}$ in the Northeastern direction of the city centre. It is a medium-sized passenger airport with 17,8 million passengers in 2007.

While the airport is divided into 9 zones [1] (Figure 1), the most relevant zone in this paper is the terminal, as it is the origin or destination of virtually all passengers.

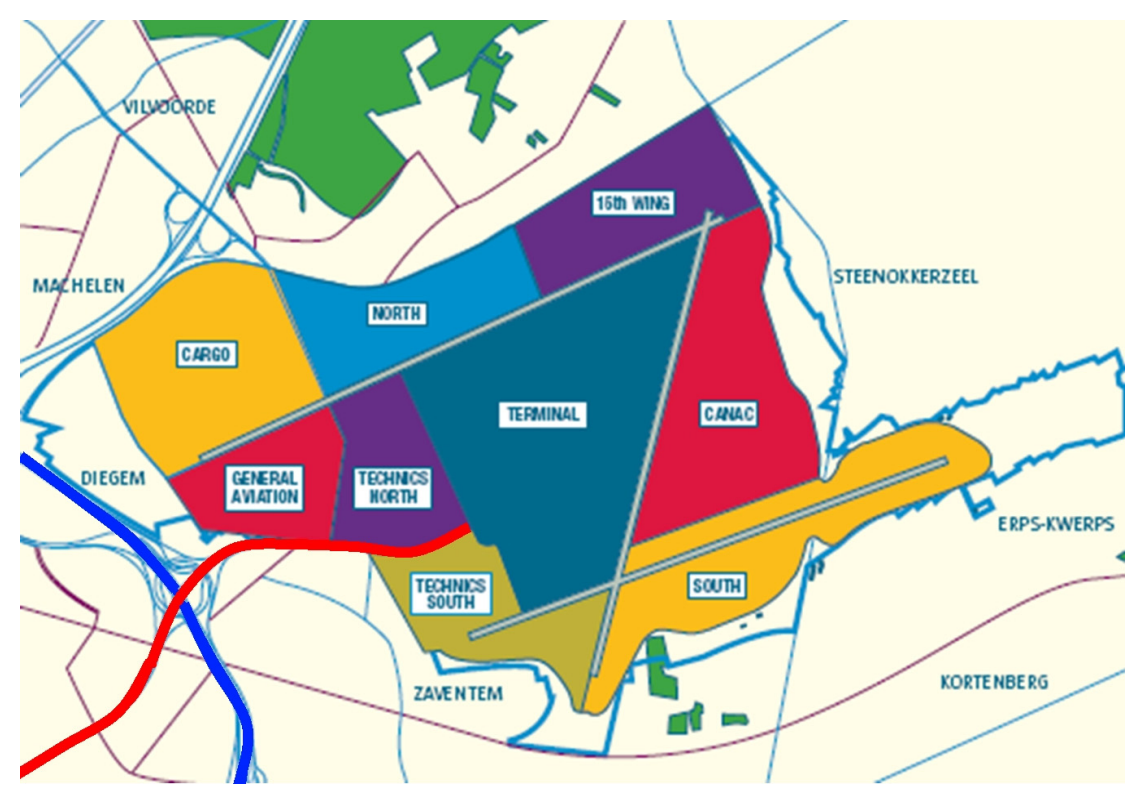

Figure 1: $\quad$ Brussels Airport is divided into 9 different zones. The ringroad highway is indicated in blue, while the A201 highway is indicated in red. Adapted from [1].

In 2006, Brussels Airport was the sixth most important cargo airport in Europe. As a consequence, the cargo area and the other zones also create some important mobility burden to and from Brussels airport, as an important part of the workers of the airport are employed there. 7921 people were employed in the terminal zone in 2006, while the cargo zone of the airport provided employment to 4036 people. Altogether, more than 20.000 people were employed in 261 companies located in the different airport zones [1]. Although these numbers are relatively limited compared to the 15,3 million Origin and Destination (or O\&D passengers $=$ total number of passengers excluding the passengers in transit) passengers travelling through the airport that same year. This limited amount of people induces a relatively high mobility burden, as the employees commute to the airport 5 to 6 times weekly. Although the focus of this paper is on passenger transport, it is clear that the important amount of cargo handled on the airport grounds induces some additional mobility burden on the surrounding highways, 
as there is no cargo railway facility in Brussels airport. In 2007, the cargo handled in Brussels airport amounted to 780.000 tons approximately, which corresponds to an increase of $69 \%$ as compared to 1996 . Currently the numbers of passengers and employees are lower than they were in the year with the highest activity (2000). Back then 26.748 people were employed and over 21 million passengers were travelling through the airport [2]. The 9/11 events and the bankruptcy of the national flag carrier Sabena explain this sharp drop in both traffic and employment since 2001 .

\section{The current situation: personal vehicles are predominant}

\subsection{Individual mobility facilities}

Seven parking lots are located within walking distance of the airport terminal (Figure 2) and present a total capacity of approximately 11.700 vehicles (Table 1). Moreover there is more distant parking for passengers in the North airport zone, which is connected to the terminal through a shuttle bus.

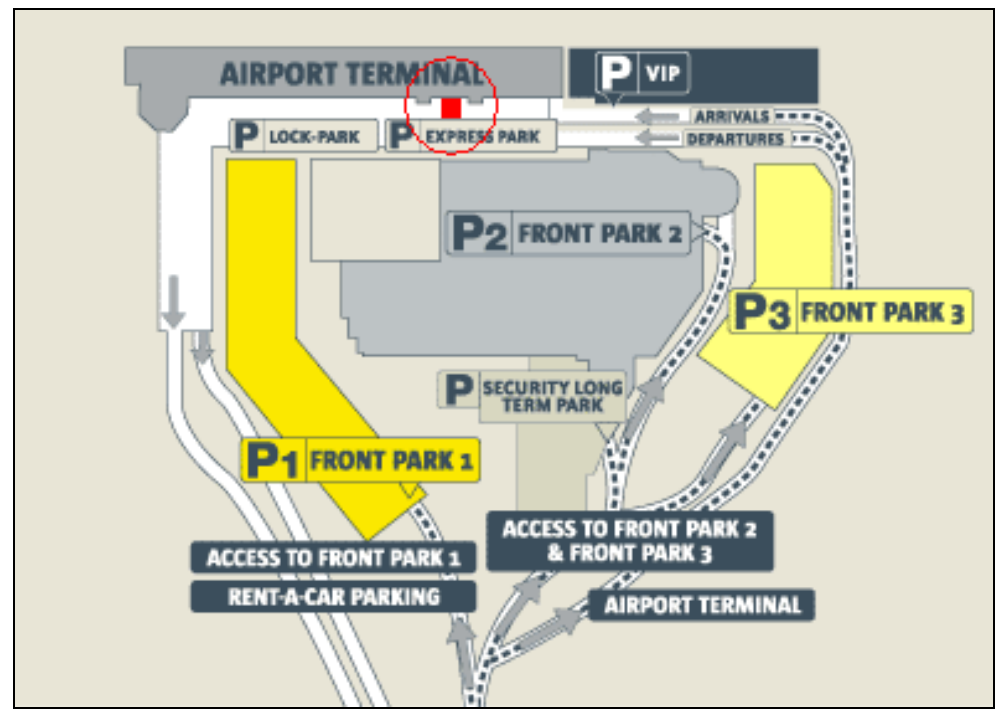

Figure 2: $\quad$ Spatial distribution of the main parking around the terminal [3].

\subsection{Public transport services}

While the number of vehicles parked on the airport parking lots remained more or less stable, the amount of people using public transport to reach or to leave the airport has been growing over time during the last years [1]. Nevertheless, the share of public transport in the airport connections is still limited. As far as public transport is concerned, the airport is currently connected through railways and through public buses. The current situation is described below. 
Table 1: $\quad$ Capacity of the different airport parking lots [4].

\begin{tabular}{|l|c|}
\hline Name Parking Lot & Capacity \\
\hline Front Park 1 & 2955 \\
\hline Front Park 2 & 3465 \\
\hline Front Park 3 & 2400 \\
\hline Express Parking & 164 \\
\hline Lock Parking & 1155 \\
\hline Security Long-Term Parking & 1088 \\
\hline VIP-parking & 515 \\
\hline Total & 11742 \\
\hline
\end{tabular}

\subsubsection{Railways}

The airport is connected to the three main railway stations in the city centre of Brussels (Brussels-North, Central and South) 4 times an hour, except for a nightly period of 5 hours, approximately between 1 am and 6 am, during which no trains are operated. The journey lasts between 16 and 30 minutes depending of the city centre station. A limited number of other trains link the airport with other cities in Belgium. Table 2 shows that the amount of people travelling to and from the airport by train has increased by $30 \%$ from nearly 2,1 million in 2002 to more than 2,7 million in 2006.

Table 2: $\quad$ Yearly amount of train users to and from Brussels airport, 20022006 [1].

\begin{tabular}{|c|c|c|c|c|}
\hline 2002 & 2003 & 2004 & 2005 & 2006 \\
\hline 2086387 & 2178509 & 2311471 & 2427291 & 2717415 \\
\hline
\end{tabular}

The current railway connection of Brussels airport is performed through a side track of the Brussels-Leuven-Liège railway (Figure 6). The airport station is currently positioned on a dead-end track. For the train connection from other railway stations in Brussels (mainly Brussels-Schuman and BrusselsLuxembourg), the railway connection with the airport is not yet optimal, as changing trains is always required. This makes a rail transfer from these stations longer and less convenient than the bus connection, which is described in the next paragraph.

\subsubsection{Public buses}

The public city transit company of Brussels (MIVB-STIB) operates a dedicated express public bus line connecting the European district the city centre and the airport terminal in approximately 30 minutes (Airport line). This line focuses on businessmen and women as well as on tourists visiting Brussels and Belgian travellers heading to or from the airport. An important share of the bus passengers consists of employees as well. Moreover, the public bus company of the Flemish region (De Lijn) recently extended its 7 original bus lines operating 
to and from the airport to a denser grid consisting of 17 local bus lines connected 5 of the 9 airport zones through 11 bus stops (Figure 1). These bus lines are the result of an intention that was expressed by the regional government to reach $40 \%$ of passengers using public transport to reach the airport by 2020 . This grid especially focuses on the employees working in the airport region and living in the vicinity of the airport (within an area of $20 \mathrm{~km}$ from the airport) as these induce approximately half of the movements in the area. Similarly to the railway services, none of the bus services are operated at night.

The number of people using the public bus services to and from the airport sharply increased during the last few years. The most spectacular increase in passenger numbers is obtained by the airport line of the MIVB-STIB, which transported over 2 million people in 2006 (Table 3).

Table 3: $\quad$ Bus user statistics to and from Brussels Airport, 2003-2006 [1].

\begin{tabular}{|l|c|c|c|c|}
\hline & 2003 & 2004 & 2005 & 2006 \\
\hline 7 original lines* & 228435 & 281871 & 329380 & 376000 \\
\hline Airport Line & 299668 & 314000 & 1604194 & 2.088798 \\
\hline
\end{tabular}

*The 7 original lines concern the bus lines of De Lijn before the recent extension with additional 10 lines.

Overall, in 2004, approximately $20 \%$ of the passengers coming from or going to the airport used public transport services, of which $15 \%$ used the railways and $5 \%$ used the buses [8]. The most recent data concerning employees' mobility date from 2001 [9] and show that, back then, only $2 \%$ used public transport. However, looking at the increasing number of people using bus and train services, the previous number are likely to have changed since, however, no new official data are available to demonstrate that assumption yet.

Next to the public bus companies, an hourly private bus service is offered to Antwerp and shuttle buses bring employees from the terminal of the airport to the different zones of the airport every 15 minutes [5].

\subsection{Limitations to the current developments}

Even though passenger numbers sharply dropped in 2001, between 1990 and 2007, passenger numbers doubled (Figure 3) and handled volumes of cargo strongly increased as well. Moreover new economic development in the airport and in the direct vicinity of the airport also strongly increased the traffic in that area. This traffic implies important air quality depletion and additional noise pollution around the airport. Therefore, it is essential to try to reduce the environmental burden of transport to and from the airport in the future. An improvement of public transport seems to be the key method to reach this objective.

Figure 3 shows that although the number of passengers on Brussels Airport is still lower than in 2000, it still more than doubled between 1990 and 2007. On 


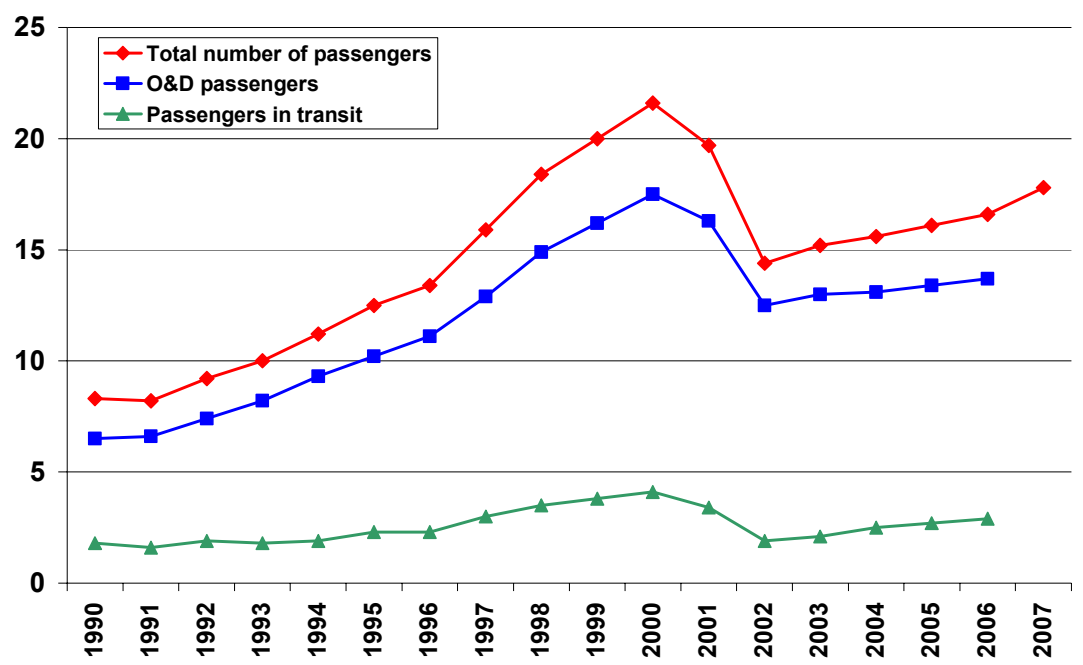

Figure 3: The evolution of the annual number of passengers (in millions) [1].

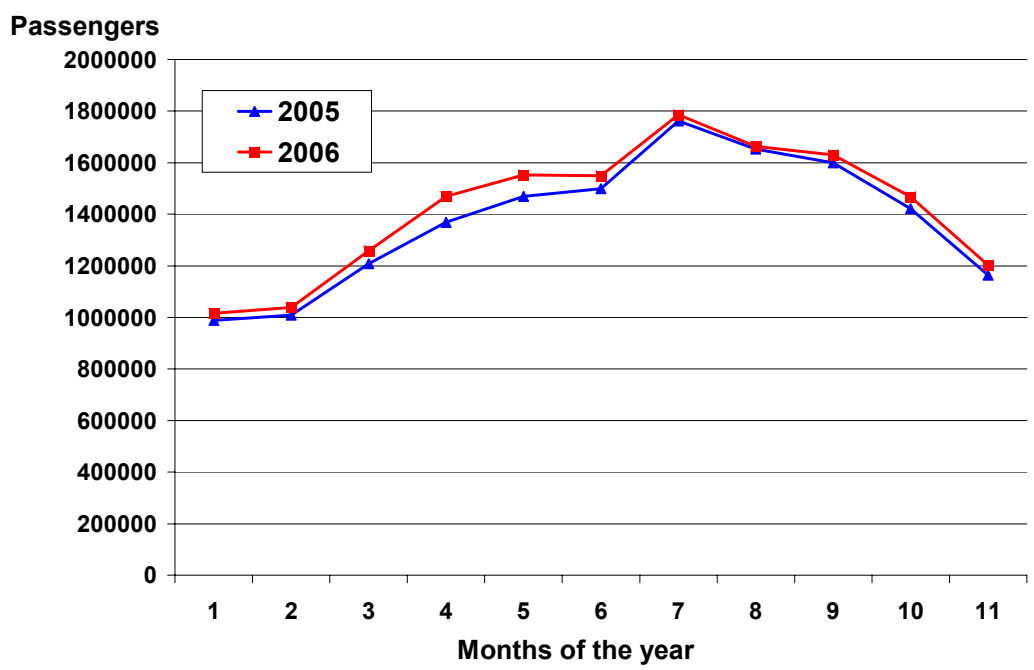

Figure 4: $\quad$ Monthly passenger numbers in Brussels Airport, in 2005 and 2006 [1].

average, in 2005 and 2006, the share of O\&D passengers was of $91 \%$ of the total [1]. Assuming the share of O\&D passengers slightly decreased to $90 \%$ in 2007 , due to the start of new intercontinental routes to/from Brussels, it means that approximately 16,0 million passengers generated a mobility burden on the roads and railroads to and from the airport. Moreover the distribution of the passenger traffic is not spread homogeneously during the day, neither during the year. Traditionally, July and August show the highest traffic intensity (Figure 4), while peak hours occur between approximately 8 and 11 am, as well as between 5 and 
8 pm. In 2006, during the busiest days, more than 60.000 daily passengers showed up at the airport, while less than 27.000 did in the least busy days.

The peak activity hours of the airport partly correspond to the "conventional" rush hours on the road. Regrettably for the fluidity of the ringway and for the road accessibility of the airport, the portions of the highways serving the airport present structural congestion during morning and evening rush hours (Figure 5). Both phenomena thus negatively influence each other.
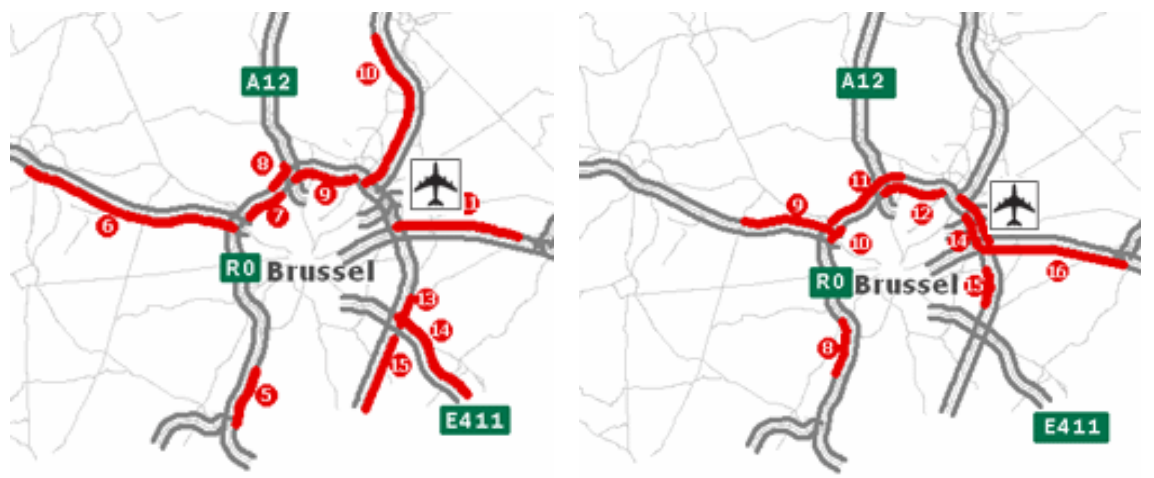

Figure 5: Structurally congested highways around Brussels airport during the morning rush hour (left) and the evening rush hour (right) [6].

The most important road connection to the airport is the A201 highway, which connects the centre of Brussels, as well as the ring road (R0) to the airport terminal. In turn, the ring road connects to the highways heading to the country's main cities. This highway also provides access to the different parking lots of the passenger terminal. This results in adding the traffic to and from the airport to the "through traffic" on the ring road and on other highways [7].

In 2004 approximately $80 \%$ of the arriving and departing passengers used a personal vehicle (private car, taxi, rental car...) to reach or leave the airport [8]. A slightly older study indicated that virtually all $(98 \%)$ of the workers active on Brussels Airport used their car to commute to the airport [9]. 93\% were driving alone to work, while 5\% were carpooling. Even if these numbers are slightly outdated, they indicate the dominance of the personal vehicles among the different transport modes of airport commuters. The airport currently being wellconnected to the highway infrastructure and highways not yet reaching full-time saturation, as well as sufficient parking space around the terminal explains the very important share of airport passengers and employees using individual passenger cars to reach the airport.

\section{The future situation: development of public transport}

Figure 6 describes the current and future developments of the railway system around the airport. Until 2005, the airport was only offering direct trains to Brussels and to a couple of cities in the West and Southwest of the country 
(mainly Ghent and Mons). Since the construction of the Nossegem curve, the offer has been extended to the East of the country (mainly direct trains to Leuven and better offer to Liège). Currently the main shortcoming of the train offer is the Northwards connection to Mechelen, Antwerp and The Netherlands. This is currently being corrected by building a new track to the North, which should be ready by 2012. Not only this track will offer a direct connection between Antwerp and the airport, it will also create an additional connection between Brussels and Antwerp, one of the most crowded connections in Belgium, through the airport. In a later phase this might also lead to a high-speed train connection between Brussels airport and The Netherlands.

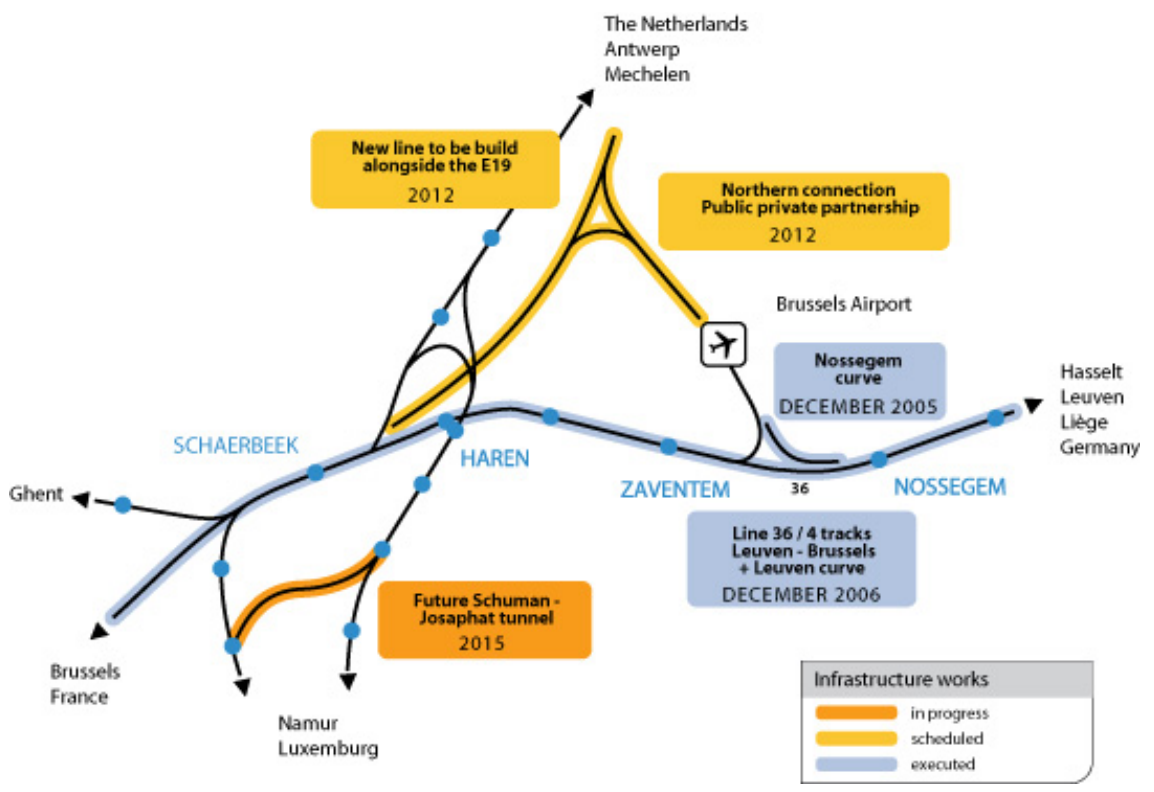

Figure 6: The current and future railway connection to Brussels Airport [2].

On a more local scale, the construction of the Josaphat tunnel, to be achieved in 2015, will improve the connection of the European district with the airport through direct trains to and from the Brussels-Schuman and BrusselsLuxembourg train stations. Moreover, a projected lightrail (a so-called tramtrain) line from the Northwestern part of Brussels through the city to the airport will also improve the service to the airport from that part of the city.

\section{Analysis and recommendations}

Currently, Brussels airport doesn't have a direct connection with the international high-speed train network, as most of the high-speed trains connecting Brussels with France, The Netherlands, Great-Britain and Germany 
only stop in Brussels-South station and not at Brussels airport. This might be solved in the future thanks to the construction of the Northern track.

IDEA Consult et al. [2] developed three development scenarios for the number of passengers travelling through Brussels airport. The different scenarios predict a potential growth from the current situation to figures ranging from 30 million (assuming a minor hub development) to 52 million (assuming the full development as an intercontinental hub) yearly passengers. Depending on the assumptions, the share of O\&D passengers, which are the only ones who influence the mobility burden to and from the airport, can fluctuate. As these scenarios didn't really take into account the increasing oil prices, which might hamper the development of the aviation sector, the most likely scenario seems to be the minor hub scenario. In the different scenarios the total number of O\&D passengers range from 26 to 28 million, as compared to the current 16 million O\&D passengers. This is approximately twice as much as the current number of O\&D passengers. Moreover, if the objective of $40 \%$ of people using public transport to reach the airport is to be achieved, it means that at least approximately 10,4 million passengers will use public transport by 2025 , as compared to the current 3 million passengers. Please note that these figures don't correspond to the actual number of people using public transport; as they don't take the mobility needs of the employees of the airport area into account. As it is commonly understood that one million passengers result in approximately 1000 direct jobs in the airport and 2000 indirect jobs in the area, this expected increase in the passenger numbers by 13 million a year would result in an estimated 13.000 jobs on the airport, and twice as much in the airport region. Taking this into account, the current planned developments are not expected to be sufficient to absorb this amount of commuters. Knowing that the connection from the European district to airport will be improved in the near future and that the connection to the three main train stations is quite well developed, it would be advisable to implement new connecting lines in other parts of the city. The current metro lines in Brussels carry 30 million passengers a year on average [10]. Therefore, looking at the expected high numbers of people travelling to and from the airport in the future, a new metro line is likely to be required in the future. Currently, a tramline is being built from the internal ring line (lines $23,24,25)$ to the first part of the A201 highway. This tramline is expected to be extended in the direction of the airport until the NATO headquarters in the coming years. To our opinion, the advisable additional connection to the airport is an extension from this tramline as an express tramline in a first phase. At the same time, it should be taken into account that this tram line could need a transformation into a metro line in the mid-term, not only for the people expected to head to or from the airport in the future, but also the numerous residents and commuters working along this axis.

\section{Conclusions}

It is clear that currently, private vehicles have a dominant position in the accessibility of the airport. In their vast majority these vehicles use the ring road 
and the A201 highway to reach the airport and this traffic gets intertwined with the yet structurally congested "through traffic" on these roads. This structural congestion on highways to and from the airport form a major bottleneck to the fluent and sustainable connection of Brussels airport with its hinterland as well as on the development of the airport itself. Although some improvements are on their way to improve the accessibility of the airport by public transport, the expected development of the airport in the future and the pollution resulting from the congested roads to the airport makes clear that an increased development of public transport to and from the airport is required in the short to medium term. Looking at the expected numbers of passengers and employees, the advisable solution seems to be the extension of the new tramline from the A201 to the NATO and the airport, keeping in mind the infrastructure (new tunnels/bridges) should be compatible with more intensive metro operation in the future, to avoid unnecessary heavy and long-lasting works in the future.

\section{References}

[1] The Brussels Airport Company (2007). Brutrends 2006. Zaventem: The Brussels Airport Company.

[2] IDEA Consult, Adecs Airinfra, Belconsulting, Stratagem en Transport \& Mobility Leuven (2005). "Trends in de luchtvaart en concurrentiepositie Zaventem". Brussels, Ministry of the Flemish community.

[3] Brussels Airport (2008). http://www.brusselsairport.be Consulted in February 2008

[4] Peersman P. (2008). Brussels airport mobility manager. Personal communication, $13^{\text {th }}$ February 2008

[5] Peersman P. (2007). Brussels airport mobility manager. Personal communication, $27^{\text {th }}$ November 2007

[6] Vlaams Verkeerscentrum (2008). Structurele ochtend- en avondfiles. Structural morning and evening traffic congestion.http:// www.verkeerscentrum.be/verkeersinfo/structurele_ochtendfiles consulted in April 2008.

[7] Province of Vlaams-Brabant (2008). http://www.vlaamsbrabant.be/ mobielzijn/luchthaven consulted in March 2008.

[8] Tritel (2004). Organisation of the parking on Brussels airport.

[9] Tritel (2001). Analysis of the commuting situation of the employees of the companies located on Brussels Airport.

[10] MIVB-STIB (2004). De MIVB in 2020 - La STIB en 2020. http://stib.be/stib-mivb-2020.html?l=nl consulted in March 2008. 